\title{
Determination of Dinotefuran and Thiamethoxam Residues in Pepper Fruits under Greenhouse Conditions using the QuEChERS Method and HPLC/DAD
}

\author{
M. M. Rabea ${ }^{1}$, E. S. Ibrahim ${ }^{1}$, D. Elhafny ${ }^{2}$ and M. A. Bayoumi ${ }^{1^{*}}$ \\ ${ }^{1}$ Department of Economic Entomology and Pesticides, Faculty of Agriculture, Cairo \\ University, Egypt. \\ ${ }^{2}$ Pesticides Residues and Environmental Pollution Dept., Central Agricultural \\ Pesticides Laboratory, Agricultural Research Center, Giza, Egypt.
}

\begin{abstract}
$\mathbf{D}^{1}$ ETERMINATION of dinotefuran and thiamethoxam residues levels in pepper samples which were collected randomly at $0,1,3,5,7,10,15$ and 21 days after treatment using quick, easy, cheap, effective, rugged, safe (QuEChERS) method and clean up step utilizing solidphase extraction (SPE) followed by determination by high-performance liquid chromatography with diode-array detection (HPLC/DAD). Dinotefuran and thiamethoxam were recovered within $77-80 \%$ and $78-112 \%$, respectively at the spike levels $(0.01-1 \mathrm{mg} / \mathrm{kg})$ in pepper samples with relative standard deviations (RSDs) lower than 3\%. Good linearity was achieved for dinotefuran and thiamethoxam with an excellent correlation coefficient of $\mathrm{R}^{2} \geq 0.996$ and the matrix matched calibration also showed good linearity with determination coefficients $\mathrm{R}^{2} \geq$ 0.98. The initial deposits of dinotefuran and thiamethoxam in pepper fruits were 6.59 and 1.38 $\mathrm{mg} / \mathrm{kg}$, respectively. The half-life period $\left(\mathrm{RL}_{50}\right)$ of tested pesticides on pepper fruits were 2 and 3.11 days for dinotefuran and thiamethoxam, respectively. According to maximum residue level (MRL) $(0.01 \mathrm{mg} / \mathrm{kg}$ for dinotefuran and $0.7 \mathrm{mg} / \mathrm{kg}$ for thiamethoxam) the pre-harvest interval (PHI) was 11 and 4 days, respectively.
\end{abstract}

Keywords: Dissipation, Determination QuEChERS, Dinotefuran, Thiamethoxam, HPLC-DAD and Pepper.

\section{Introduction}

Neonicotinoid insecticides including imidacloprid, acetamiprid, thiacloprid, thiamethoxam, clothianidin, and dinotefuran are effective insecticides to control pest with novel modes of action [1].

Pesticides are widely applied to vegetables and fruits to guarantee their quality and to fulfill the consumer's requirements and for the trade. However, these compounds can be unsafe for humans, according to the levels of pesticides present. So, the European Union Council Directive 91/414/EEC controlled the maximum concentrations of these molecules [2]. On the other hand, MRLs for neonicotinoid insecticides residues have been established by The United States EPA in the range $0.02-6 \mathrm{mg} \mathrm{kg}^{-1}$ in different types of vegetables and fruits depending on the different pesticides and matrixes (http://www. mrldatabase.com).

The evaluation of pesticide residues in food matrices is a tremendous challenge mainly because the amounts of analytes are small compared to the huge quantities of interfering substances which strongly interact with analytes[3]. QuEChERS has been developed as a new sample preparation methodology between 2000 and 2002 for pesticide multiresidue analysis[4]. Generic extraction procedures, like QuEChERS method and ultrahigh-performance liquid chromatography systems

*Corresponding author e-mail: mohammedabdallah851@agr.cu.edu.eg

DOI: 10.21608 /ejchem.2018.2803.1227

C2017 National Information and Documentation Centre (NIDOC) 
combined with polar embedded $\mathrm{C} 18$ phases, providing excellent peak shape and good resolution, enabled us to detect a wide spectrum of compounds which belong to different pesticides classes and chemical properties in each sample[4, 5].

Acetone, ethyl-acetate, methanol and acetonitrilebased sample extraction techniques are generally used for multi-class pesticides which are typically followed by a clean-up step [6]. Several methods have been reported for the analysis of neonicotinoids (thiamethoxam, imidacloprid, and acetamiprid), for example, HPLC coupled with ultraviolet detection (HPLC-UV), HPLC diode array detection (HPLCDAD) or HPLC mass spectrometry (HPLC-MS) are used for the determination of imidacloprid in different environmental samples [7, 8]. HPLC-DAD is a technique with more widespread use and suitable for the separation and quantification of compounds with high molar absorptivity, such as neonicotinoids [9].

Greenhouses production of crops requires pesticides applications due to high liability of the crops to be infected with many pests, such as aphids, thrips and whiteflies, which cause economic injury to pepper through direct injury, virus transmission, leaf stunting, yellowing and curling on mature plants.

The objective of the present work was to determine the dissipation behavior and the residues of dinotefuran and thiamethoxam in pepper fruits under greenhouse conditions.

\section{Materials and methods}

Materials

\section{Chemicals and reagents}

Certified reference standard of thiamethoxam and dinotefuran (Fig. 1) $>98 \%$ purity was obtained from Central Agricultural Pesticides Laboratory (CAPL). Acetonitrile of HPLC grade was purchased from Merck. Bulk primary secondary amine (PSA) sorbent (Bondesil-PSA, $40 \mu \mathrm{m})$ was bought from Subelco. Anhydrous magnesium sulfate and sodium chloride were purchased from Merck. Anhydrous magnesium sulfate and Sodium chloride were activated by heating at $250^{\circ} \mathrm{C}$ for $4 \mathrm{~h}$ in the oven before use and kept in desiccators. Pesticide technical formulations (Actara 25\% WG), was supplied by Syngenta Agro, Egypt and (Oshin 20\% SG), was supplied by Shoura Company, Egypt.

\section{Apparatus}

Agilent 1100 HPLC equipped with diode array detector (Agilent, Palo- Alto, CA USA) at UV wavelength 230 and $210 \mathrm{~nm}$ for thiamethoxam and dinotefuran. An ODS C18 HPLC column (4.6 $\mathrm{mm}{ }^{\prime} 150 \mathrm{~mm}{ }^{\prime} 5 \mu \mathrm{m}$ ) was used as the separation column. Mobile phase consisted of acetonitrile and water (90:10) and (60:40) for thiamethoxam and dinotefuran, respectively with a flow rate of $0.8 \mathrm{ml} / \mathrm{min}$. The retention time of thiamethoxam and dinotefuran under these conditions was 2.34 and $1.98 \mathrm{~min}$, respectively.

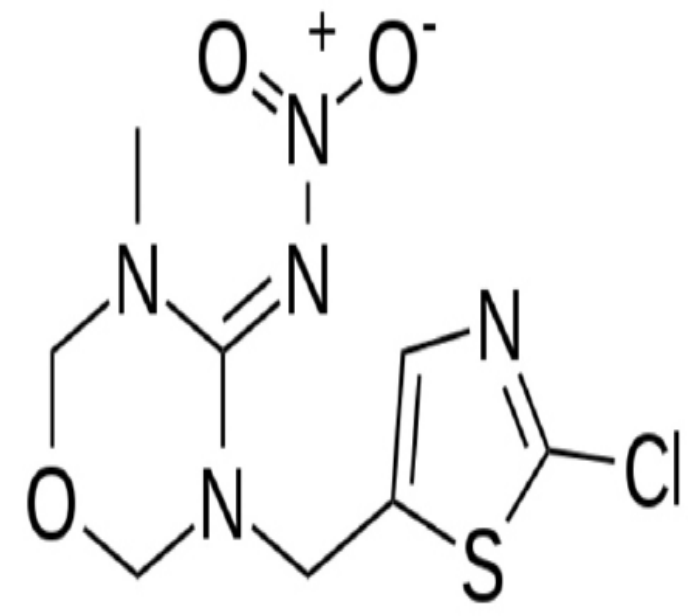

a. Thiamethoxam

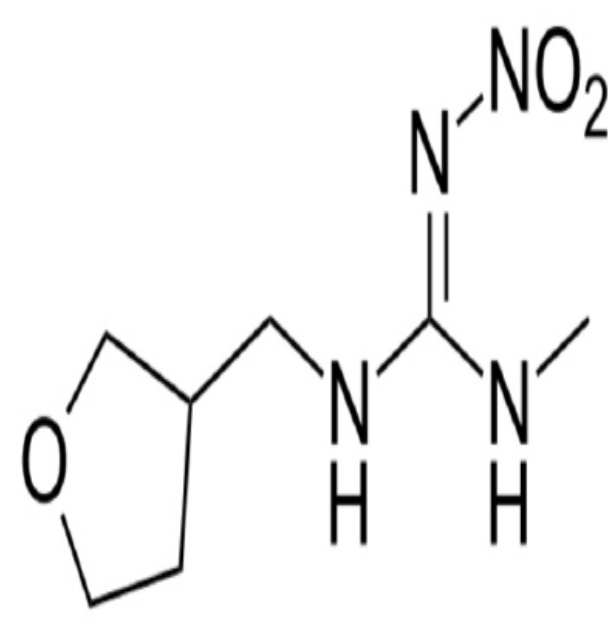

b. Dinotefuran

Fig. 1: Structure of thiamethoxam and dinotefuran 


\section{Standard preparation}

Stock solutions of thiamethoxam and dinotefuran were prepared by dissolving $10 \mathrm{mg}$ of the analytes (of accurate weight) in $100 \mathrm{ml}$ ethyl acetate and methanol, respectively to obtain solution concentration of $0.1 \mathrm{mg} / \mathrm{ml}$. Working standard solutions of 10, 5, 2, 1, 0.5, 0.1 and 0.01 $\mu \mathrm{g} / \mathrm{ml}$ of each were prepared by appropriately diluting the stock solutions with methanol. Stock solutions were stored at $-20 \pm 2{ }^{\circ} \mathrm{C}$, and working standard solutions were stored in the dark $£ 4{ }^{\circ} \mathrm{C}$ when not in use.

\section{Field experiment}

Field experiment was carried out in experimental farm of Faculty of Agric. Cairo Univ. during 2016 season. Pepper plants were sprayed by dinotefuran (Actara 20\% SG) at $125 \mathrm{~g} / 100-$ liter water and thiamethoxam (Oshin 25\% WG) at the recommended rate $20 \mathrm{~g} / 100$-liter water to determine the residues of these chemicals in pepper fruits. Random samples of the fruits were collected from the treated plants 0 , $1,3,5,7,10,15$ and 21 days' post application for dinotefuran and thiamethoxam.

\section{Sampling and storage:}

Sampling was performed by randomly collecting $2 \mathrm{Kg}$ of pepper from each untreated and treated areas (thiamethoxam and dinotefuran). The collected samples were representative of all plants in the area. First clean samples of pepper were collected from the control area, and then treatment of plants started on the previously mentioned dates, and sampling took place $2 \mathrm{~h}$ after application of the initial deposits, repeated 1 , $3,5,7,10,15$ and 21 days afterwards to study the dissipation of the pesticides. Field samples were transported in iceboxes to the laboratory.

\section{Extraction and clean up.}

The samples were extracted with modified QuEChERS method [10], $10 \mathrm{~g}$ of weighed chopped sample (blank or spiked) was shaken with $10 \mathrm{ml}$ of acetonitrile in a 50-ml centrifuge tube then $4.00 \mathrm{~g}$ of anhydrous magnesium sulfate was added, and shaken for 1 minute. The tube was vortexed and centrifuged for 5 minutes at 4000 rpm. $6 \mathrm{~mL}$ of acetonitrile layer was transferred into a Polipropilene-single centrifuge tube which contains $150 \mathrm{mg}$ PSA and $900 \mathrm{mg}$ magnesium sulfate anhydrous. The sample was mixed vigorously by vortexing for $1 \mathrm{~min}$ and centrifuge extracted for 2 minutes at $6000 \mathrm{rpm}$.

Method validation

The linearity of a method is a measure of range within which detector response is directly proportional to the concentration of analyte in samples. Standard solutions in terms of microliters, at variable concentrations, were divided into individual amounts, with the interval $0.01,0.1,0.5,1,2,5$ and $10 \mathrm{mg} / \mathrm{kg}$ for injected solutions. The tests were repeated for three times at each concentration, proving favorable linear relationship of the pesticides. Correlation coefficients were 0.99 for dinotefuran and thiamethoxam.

Matrix-matched calibration (MMC) was used to compensate for the matrix effects. The matrix effects were defined as the influence of one or more co-extracted components from the sample on the measurement of thiamethoxam and dinotefuran concentration. The presence of these effects is demonstrated by comparing the response produced from the thiamethoxam and dinotefuran in a pure solvent solution with the samples were first extracted and then spiked with thiamethoxam and dinotefuran in the same solvent at the same concentration levels $(10,5,2,1,0.5,0.1$ and 0.01 $\mathrm{mg} / \mathrm{kg}$ ).

Matrix effects (\%ME) were calculated using the equation:

$$
\text { ME } \%=\frac{M \text { matrix }-M \text { solvent }}{M \text { solvent }} \times 100 \%
$$

where

ME: the matrix effect

M matrix: Slope of calibration curve in matrix. M solvent: Slope of calibration curve in the pure solvent.

LOD means the validated lowest residue concentration which can be quantified by routine monitoring with validated control methods defined as a signal-to-noise ratio $(\mathrm{S} / \mathrm{N})$ of $3: 1 . \mathrm{LOQ}$ is the lowest concentration of the analyte that has been validated with acceptable trueness (70-120\%) and precision ( $\mathrm{RSD} \leq 20 \%$ ) by applying the complete analytical method defined as a signal-to-noise ratio (S/N) of 10:1. According to Dg-sanco, 2013 [11], the Limit of quantification should be $\leq$ MRL .

The trueness was determined from the recovery assay results of samples spiked with all the analytes at the levels $(0.01-1 \mathrm{mg} / \mathrm{kg})$, five replicates per level used to check the recovery at acceptable mean recoveries are those within the range of $70-120 \%$.

Trueness was calculated using the following

Egypt. J. Chem. 61, No. 2 (2018) 
equation:

$$
\% \mathrm{R}=(\mathrm{X} / \mu) \times 100
$$

$\% \mathrm{R}$ : recovery percentage

$\mathrm{X}$ : experimental concentration of dinotefuran or thiamethoxam $\mathrm{mg} / \mathrm{kg}$

$\boldsymbol{\mu}$ : calculated concentration of dinotefuran or thiamethoxam $\mathrm{mg} / \mathrm{kg}$

The precision is a measure of how close results are to another one (Repeatability (r)) was defined as standard deviation of measurement of dinotefuran or thiamethoxam obtained using the same method on the same samples in a single laboratory over a short period of time, during which differences in the materials and equipment used and analysts involved will not occur. The value of $\leq 20 \%$ was used as the limit for RSD. Five replicates for each recovery levels $(0.01-1 \mathrm{mg} / \mathrm{kg})$ per day on three different days were used to check the precision.

$$
\% \mathrm{RSD}=(\mathrm{SD} / \mathrm{M}) \times 100
$$

where

SD: standard deviation of the replicates.

$\mathrm{M}$ : the mean value of the recovery.

\section{Statistical analysis}

The dissipation kinetics of thiamethoxam and dinotefuran residues in pepper was determined by plotting residue concentration against elapsed time after application and equations of best curve fit with maximum coefficients of determination $\left(\mathrm{R}^{2}\right)$ were determined. For dissipation of thiamethoxam and dinotefuran in pepper, exponential relationships were found to be applicable corresponding to the general first-order kinetics equation:

$$
\mathrm{Ct}=\mathrm{C} 0 \mathrm{e}^{-\mathrm{kt}}
$$

where $C t$ represents the concentration of the pesticide residue at the time of $t, C O$ represents the initial deposits after application and $\mathrm{k}$ is the constant rate of pesticide dissipation per day. From this equation, the dissipation half-life periods $\left(t_{1 / 2}=\ln 2 / \mathrm{k}\right),[12,13,14]$ of the studied insecticide were determined.

\section{Results}

\section{Method Validation}

The evaluations of calibration curve linearity of thiamethoxam and dinotefuran were done based on injections of standard solutions prepared in pure organic solvent methanol in series at $(10$, 5, 2, 1, 0.5, 0.1 and $0.01 \mathrm{mg} / \mathrm{kg}$ ) for HPLC-DAD. Standard calibration curve of thiamethoxam and dinotefuran was constructed by plotting analyte concentrations against peak areas. The correlation Egypt. J. Chem. 61, No. 2 (2018) coefficient $\left(R^{2}=0.99\right)$.

The pesticide residue analysis study, the injected sample contained large amounts of the unavoidably present co-extractives which are responsible for the matrix effects occurring on the injector. The matrix effect was investigated by comparing the slopes of calibration curves at (10, $5,2,1,0.5,0.1$ and $0.01 \mathrm{mg} / \mathrm{kg}$ ) of dinotefuran and thiamethoxam in pepper and in pure solvent. The $\% \mathrm{ME}$ could be negative or positive and would be classified in three categories: no matrix effect (between $-20 \%$ and $20 \%$ ), medium matrix effect (between $-50 \%$ and $-20 \%$ ) and strong matrix effect (below $-50 \%$ or above $50 \%$ ) $[15,16]$. The results showed that the matrix effect was $-17.75 \%$ for dinotefuran and $4.36 \%$ for thiamethoxam which indicated that no interfering endogenous peak appeared and did not significantly suppress or enhance the response of the instrument.

The lowest validated level of dinotefuran and thiamethoxam with acceptable precision and trueness LOQ was $0.01 \mathrm{mg} / \mathrm{kg}$ for HPLC analysis in pepper. According to Dg-sanco, 2013 [11], the LOQ values are acceptable where LOQ $\leq$ MRL $(0.01$ and $0.7 \mathrm{mg} / \mathrm{kg}$ for dinotefuran and thiamethoxam, respectively.

The trueness, bais or mean of recovery was carried out in 5 replicates at 3 fortification levels $(1,0.5,0.01 \mathrm{mg} / \mathrm{kg})$ by spiking $10 \mathrm{~g}$ of blank samples with standard solution. The obtained mean recoveries range from $77-80 \%$ and $78-112 \%$ for dinotefuran and thiamethoxam, respectively with relative standard deviation $(\% \mathrm{RSD})$ ranged from 2.08 to 2.51 and from 1.92 to 2.14 . According to Dg-sanco, 2013 [11], the found mean recoveries were in the acceptable range (70-120\%). So, the value showing that the method was sensitive and suitable for the determination of dinotefuran and thiamethoxam residue in pepper.

The repeatability precision $(\% \mathrm{RSD})$ involved repeat of recovery levels $(1,0.5,0.01 \mathrm{mg} / \mathrm{kg})$, five replicates for each level per day on three different days. The $(\% \mathrm{RSD})$ value ranged from 1.22 to 2.89 and 2.04 to 3.27 According to Dgsanco, 2013 [11], the obtained (\%RSD) value was within the acceptable range $\leq 20 \%$.

\section{Dissipation of insecticide thiamethoxam and dinotefuran in pepper. \\ Thiamethoxam \\ Dissipation of thiamethoxam in pepper fruits was studied during 21 days. The dissipation pattern of thiamethoxam in pepper at different sampling intervals $(0,1,3,7,10,15$ and 21 days $)$ is presented in Table 1 and Fig. 2. The initial deposit of thiamethoxam in pepper fruits was 1.38}


$\mathrm{mg} / \mathrm{kg}$ two hours after application. The residue of thiamethoxam in pepper fruits decreased to 1.27 $\mathrm{mg} / \mathrm{kg}$ with $7.97 \%$ loss after 24 hours of application. The dissipation continued for thiamethoxam to reach $0.72 \mathrm{mg} / \mathrm{kg}$ with $47.82 \%$ loss in the third day of application. The rapid dissipation was found in the seventh day after spraying, which thiamethoxam residue reached $0.083 \mathrm{mg} / \mathrm{kg}$ with 93.98\% loss. The degradation continued to reach $0.061 \mathrm{mg} / \mathrm{kg}$ with $95.57 \%$ loss after 10 days after application. The residues of thiamethoxam on pepper decreased to $0.034 \mathrm{mg} / \mathrm{kg}$ with $97.31 \%$ loss and $0.01 \mathrm{mg} / \mathrm{kg}$ with $99.27 \%$ loss after 15 and 21 days of application, respectively. Based on the previous results, the calculated half-life period $\left(\mathrm{RL}_{50}\right)$ of thiamethoxam on pepper fruits was 3.13 days. The maximum residue limit (MRL) of thiamethoxam in pepper fruits is $0.7 \mathrm{mg} / \mathrm{Kg}$ according to Codex Alimentarius Commission for Pesticide Residues (CAC/PR). 2009 [17]. The results presented herein clearly show that pepper fruits can be consumed safely by human after 4 days from spraying with thiamethoxam.

dinotefuran

Data presented in Table 2 and Fig. 3

TABLE 1. Dissipation of thiamethoxam residue in pepper fruits.

\begin{tabular}{cccc}
\hline $\begin{array}{c}\text { Time after } \\
\text { application }\end{array}$ & Residues $(\mathrm{mg} / \mathrm{kg}) \pm \mathrm{SD}$ & \% loss & \% persistence \\
\hline Initial & $1.38 \pm 0.54$ & 0.00 & 9003 \\
1 day & $1.27 \pm 2.87$ & 7.97 & 52.18 \\
3 days & $0.72 \pm 1.05$ & 47.82 & 28.27 \\
5 days & $0.39 \pm 2.59$ & 71.73 & 6.02 \\
7 days & $0.083 \pm 2.01$ & 93.98 & 4.43 \\
10 days & $0.061 \pm 0.54$ & 95.57 & 2.69 \\
15 days & $0.034 \pm 0.81$ & 97.31 & 0.73 \\
21 days & $0.01 \pm 0.24$ & 99.27 & 3.11 \\
RL (days) & & 0.7 & 4 \\
\hline MRL & & & \\
\hline
\end{tabular}

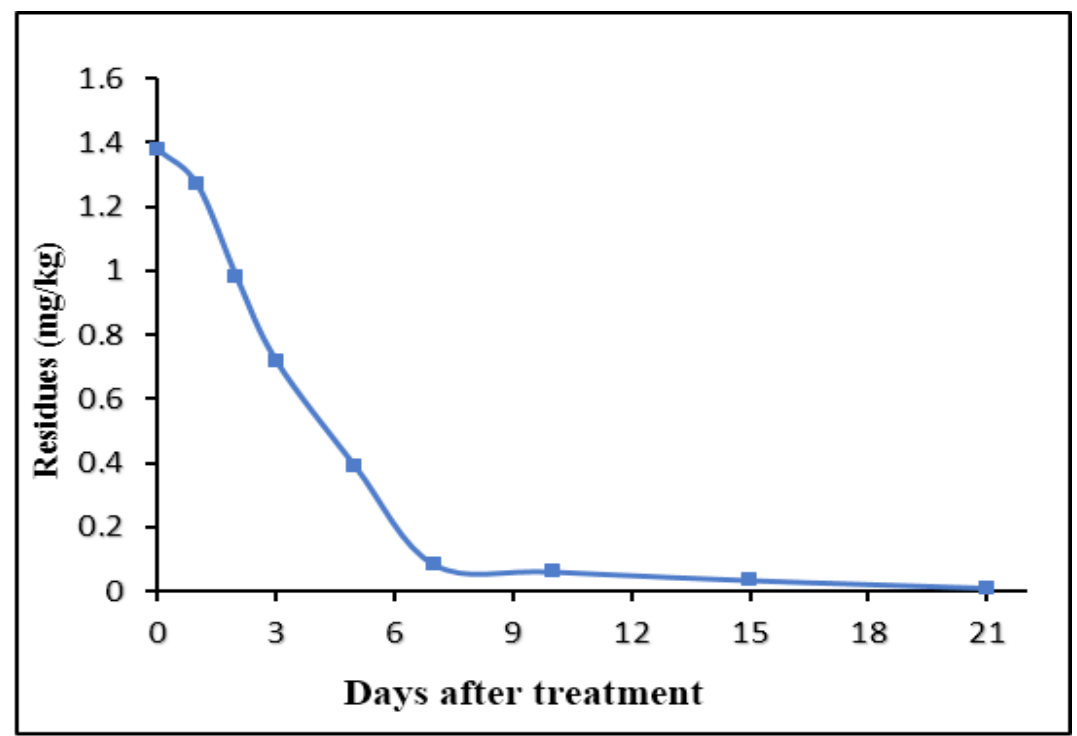

Fig. 2. Dissipation Curve of Thiamethoxam in Pepper Fruits. 
demonstrate the initial deposits as well as the residual behavior of dinotefuran in pepper fruits. The initial deposit of dinotefuran in pepper fruits was $6.59 \mathrm{mg} / \mathrm{kg}$ two hours after application. The residue of dinotefuran in pepper fruits within the first 24 hours after application decreased to $5.40 \mathrm{mg} / \mathrm{kg}$ with $18.06 \%$ loss. The amounts of dinotefuran residue decreased to $1.28 \mathrm{mg} / \mathrm{kg}$ with high percent loss $(80.58 \%)$ in the third day of application. Data indicated that dissipation of dinotefuran residue was rapidly within the first three days after spraying. Residues of dinotefuran in pepper fruits continued and reached to 0.09 and $0.01 \mathrm{mg} / \mathrm{kg}$ with 98.63 and $99.84 \%$ loss after 7 and 10 days of application, respectively. The residues became undetectable on $15^{\text {th }}$ and $21^{\text {st }}$ day after application. Based on the previous results, the calculated half-life period $\left(\mathrm{RL}_{50}\right)$ of dinotefuran in pepper fruits was 2 days. The maximum residue limit (MRL) of dinotefuran in pepper fruits is $0.01 \mathrm{mg} / \mathrm{Kg}$ according to Codex Alimentarius Commission for Pesticide Residues (CAC/PR). 2009 [17], so the pepper fruits can be consumed safely after 11 days of application.

TABLE 2. Dissipation of dinotefuran residue in pepper fruits.

\begin{tabular}{cccc}
\hline Time after application & $\begin{array}{c}\text { Residues } \\
(\mathbf{m g} / \mathbf{k g}) \mathbf{S D}\end{array}$ & $\mathbf{\%}$ loss & \% persistence \\
\hline Initial & $6.59 \pm 1.25$ & 0.00 & 100 \\
1 day & $5.40 \pm 0.95$ & 18.06 & 81.94 \\
3 days & $1.28 \pm 1.01$ & 80.58 & 19.42 \\
5 days & $0.67 \pm 1.38$ & 89.83 & 10.17 \\
7 days & $0.09 \pm 2.09$ & 98.63 & 1.37 \\
10 days & $0.01 \pm 0.22$ & 99.84 & 0.15 \\
15 days & ND & --- & -- \\
21 days & ND & --- & -- \\
\hline $\mathrm{RL}_{50}$ (days $)$ & & 2 & \\
MRL & & 0.01 & \\
PHI & & 11 &
\end{tabular}

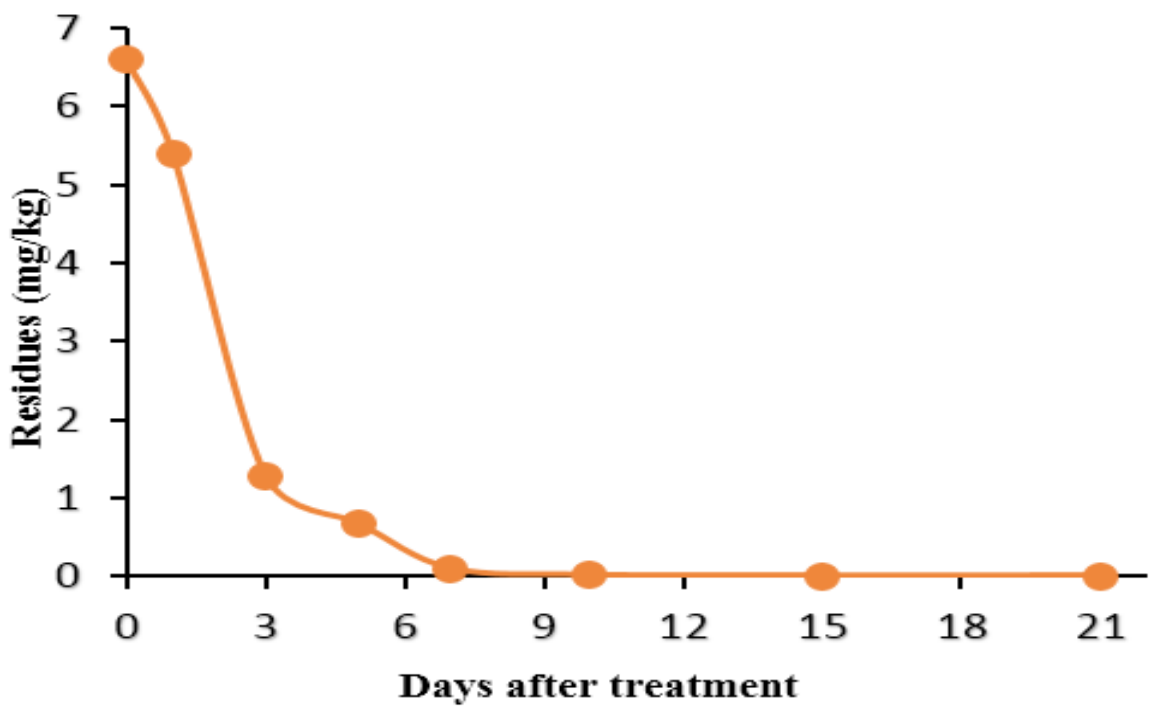

Fig. 3. Dissipation curve of dinotefuran in pepper fruits. 


\section{Discussion}

The evaluations of calibration curve linearity of thiamethoxam and dinotefuran were done with HPLC-DAD. The correlation coefficient $\left(R^{2}=0.99\right)$. The results showed that the matrix effect was $-17.75 \%$ for dinotefuran and $4.36 \%$ for thiamethoxam which indicated that no interfering endogenous peak appeared and did not significantly suppress or enhance the response of the instrument.

The residual amount of thiamethoxam was rapidly decreased during the third day of spraying followed by gradually decreasing until the end of experimental period, the lowest dissipation rate per day found from the seventh to tenth day of application, while the highest value occurred in the first 24 hours of spraying. The pepper fruits could be used safely for human consumption after 4 days from spraying with thiamethoxam, because the residues below the MRL of thiamethoxam on pepper. Also, the initial deposit of thiamethoxam (Actara 25\% WG) on pepper fruits was lower than the other tested pesticides. It may be due to that the rate of application for Actara 25\% WG (20 g/100 L water).

The highest dissipation rate of dinotefuran per day was found in the first day, a quick decline of dinotefuran concentration mainly during the first three days was observed followed by gradually decrease until the $15^{\text {th }}$ day after treatment. In the same concept, Galietta, et al 2010 [18] reported that 16 days after application pepper by dinotefuran are necessary to meet the European MRL requirements and zero days for the USA requirements. On the other hand, Rahman et al 2013 [19] found a maximum of $0.32 \mathrm{mg} \mathrm{kg}^{-1}$ of dinotefuran residue was detected in leek sample sprayed three times at 7-day intervals until 7 days prior to harvest.

The climatic conditions, dosage, the intervals between application and harvest effect on the dissipation of pesticide residues in crops, also the rapid dissipation of originally applied pesticide is dependent on a variety of environmental factors such as sunlight and temperature, however, high temperature is reported to the major factor in reducing the pesticides from the plant surface, light plays an important role in the behavior of pesticide in the environment. Also, the decline of pesticides may be due to biological, chemical or physical processes, or if still in the field, due to dilution by the growth of the crop $[20,21]$.

\section{Conclusion}

In this work, an HPLC-DAD analytical method based on QuEChERS sample pretreatment procedures was used for the determination of dinotefuran and thiamethoxam residues in pepper fruits. The developed method is easy and compatible for residue analyses of dinotefuran and thiamethoxam, the mean recoveries ranged from $77-80 \%$ and $78-112 \%$ respectively, and repeatability of the method, expressed as the relative standard deviation, was lower than $3 \%$. The calculated half-life period $\left(\mathrm{RL}_{50}\right)$ of tested pesticides on pepper fruits were 2 and 3.11 days for dinotefuran and thiamethoxam, respectively. According to maximum residue limit (MRL) the pre-harvest interval (PHI) of thiamethoxam and dinotefuran in pepper was 4 and 11 days after the treatment, respectively.

\section{Acknowledgements}

This work was supported by Faculty of Agriculture, Cairo University, Egypt.

\section{References}

1. Gupta, M.; Sharma, A. and Shanker, A., Dissipation of imidacloprid in orthodox tea and its transfer from made tea to infusion. Food Chemistry, 106 (1): 158-164 (2008). DOI: https://doi .org/10.1016/j. foodchem.05.082 (2007).

2. Directive, C., Council Directive 91/414/EEC of 15 July 1991 concerning the placing of plant protection products on the market. Official Journal of the European Communities L 230, 1-32 (1991).

3. Wilkowska, A. and Biziuk, M., Determination of pesticide residues in food matrices using the QuEChERS methodology. Food Chemistry, 125 (3): 803-812 (2011). DOI: https://doi.org/10.1016/j. foodchem. 09.094 (2010).

4. Anastassiades, M.; Lehotay, S. J.; Štajnbaher, D. and Schenck, F.J., Fast and easy multiresidue method employing acetonitrile extraction/partitioning and "dispersive solid-phase extraction" for the determination of pesticide residues in produce. Journal of AOAC international 86(2): 41243 (2003). 1. https://naldc.nal.usda.gov/naldc/ download $\cdot x h t m l ? i d=555 \&$ content $=$ PDF

5. Schreiber, A. and Pace, N., Intelligent use of retention time during multiple reaction monitoring for faster and extended compound screening with higher sensitivity and better reproducibility. Application Note AB SCIEX:1282310-01 (2010). http://

Egypt. J. Chem. 61, No. 2 (2018) 
www.absciex-korea.com/Documents/Downloads/ Literature/mass-spectrometry-MultipleReaction-1282310.pdf

6. Kmellar, B.; Fodor, P.; Pareja, L.; Ferrer, C., Martínez-Uroz, M.A.; Valverde, A. and FernandezAlba, A.R., Validation and uncertainty study of a comprehensive list of 160 pesticide residues in multi-class vegetables by liquid chromatographytandem mass spectrometry. Journal of Chromatography A, 1215 (1): 37-50 (2008). DOI: https://doi.org/10.1016/j.chroma. (2008) 10.121

7. Zhou, Q.X.; Ding, Y.J. and Xiao, J.P., Sensitive determination of thiamethoxam, imidacloprid and acetamiprid in environmental water samples with solid-phase extraction packed with multiwalled carbon nanotubes prior to high-performance liquid chromatography. Analytical and Bioanalytical Chemistry, 385 (8): 1520-1525 (2006).. DOI: https://doi.org/10.1007/s00216-006-0554-7.8. Xie, W.; Han, C.; Qian, Y.; Ding, H.; Chen, X. and Xi, J. Determination of neonicotinoid pesticides residues in agricultural samples by solid-phase extraction combined with liquid chromatography-tandem mass spectrometry. Journal of Chromatography A, 1218 (28): 4426-4433 (2011).. DOI: https://doi. org/10.1016/j.chroma.2011.05.026

9. Stoev, G. and Stoyanov, A.. Comparison of the reliability of the identification with diode array detector and mass spectrometry. Journal of Chromatography A, 1150(1):302-311 (2007). DOI: https://doi. org/10.1016/j.chroma.2006.12.026.

10. EURL-FV.2010-M1. Multiresidue Method using QuEChERs followed by GC-QqQ/MS/MS and LC-QqQ/MS/MS for Fruits and Vegetables. http:// www.crl-pesticides.eu/library/docs/fv/ CRLF V_ Multiresidue_methods. pdf.

11. Dg-sanco, E. C., Guidance document on analytical quality control and validation procedures for pesticide residues analysis in food and feed. (2013). SANCO/12571.http://www.eurlpesticides.eu/library/docs/allcrl/AqcGuidance Sanco_2013_12571.pdf

12. Hoskins, W.M., Mathematical treatment of loss of pesticide residues. Plant Protection Bulletin, (FAO), 9:163-168 (1961)..

13. Moye, H.A., Malagodi, M.H., Yoh, J., Leibee, G.L., $\mathrm{Ku}, \mathrm{C} . \mathrm{C}$. and Wislocki, P.G., Residues of avermectin $\mathrm{B}_{1} \mathrm{a}$ in rotational crops and soils following soil treatment with $\left({ }^{14} \mathrm{C}\right)$ avermectin $\mathrm{B}_{1} \mathrm{a}$. Journal of agricultural and food chemistry, 35(6), 859-864 (1987). DOI:10.1021/jf00078a003

Egypt. J. Chem. 61, No. 2 (2018)
14. Fantke, P. and Juraske, R. Variability of pesticide dissipation half-lives in plants. Environmental Science \& Technology, 47(8):3548-3562 (2013).

15. Ferrer, C.; Lozano, A.; Aguera, A.; Jimenez, A. and Fernandez, A.R., Overcoming matrix effects using the dilution approach in multiresidue methods for fruits and vegetables. Journal of Chromatography A, 1218 (42): 7634-7639 (2011). DOI: https://doi. org/ 10.1016/j.chroma.2011.07.033

16. Saber, A.N.; Malhat, F.M.; Badawy, H.M.A and Barakat, D.A., Dissipation dynamic, residue distribution and processing factor of hexythiazox in strawberry fruits under open field condition. Food chemistry, 196: 1108-1116 (2016). DOI: https://doi .org/10.1016/j.foodchem.2015.10.052

17. Codex Alimentarius Commission for Pesticide Residues (CAC/PR). . List of maximum residue limits for pesticides in food and animal feeds, (2009) http://www.codexalimentarius.net.

18. Galietta, G.; Egana, E.; Gemelli, F.; Maeso, D.; Casco, N.; Conde, P. and Nunez, S., Pesticide dissipation curves in peach, pear and tomato crops in Uruguay. Journal of Environmental Science and Health Part B, 46 (1): 35-40 (2010). DOI: https:// doi.org/10.1080/036 01234.2010.515504

19. Rahman, M. M.; Park, J. H.; El-Aty, A. A.; Choi, J. H.; Yang, A.; Park, K. H. and Shim, J. H., Feasibility and application of an HPLC/UVD to determine dinotefuran and its shorter wavelength metabolites residues in melon with tandem mass confirmation. Food Chemistry, 136 (2): 1038-1046 (2013). DOI: https ://doi.org/10.1016/j.foodchem. (2012) 08.064.

20. Christensen, H.B., Fungicides in food, analytical and food safety aspects. Ph.D. thesis. Danish Institute for Food and Veterinary Research, Denmark (2004).

21. Waghulde, P.N; Khatik, M.K.; Patil, V.T. and Patil, P.R., Persistence and dissipation of pesticides in chilly and okra at north maharashtra region. Pesticide Research Journal, 23 (1): 23-26 (2011). https://www.researchgate.net/ profile/Pradip_Patil6/publication/236229088 Persistence_and_Dissipation_of_Pesticides_in Chilly and Okra at North_Maharashtra_Region/ links/0c9605172357fb9722000000.pdf.

(Received 31/1/2018; accepted 27/2/2018) 


\section{تقدير متبقيات مبيدى داينوتيفيوران و ثياميثوكسام فى ثمار الفلقل بإستخدام طريقة

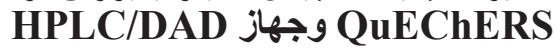

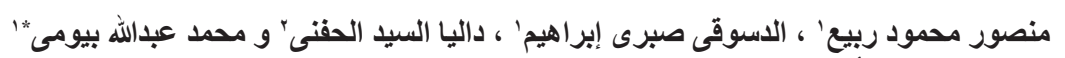

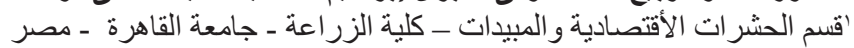

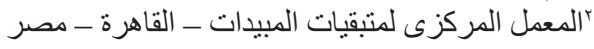

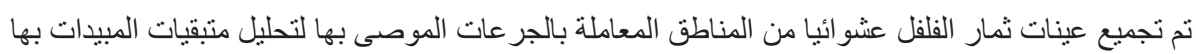

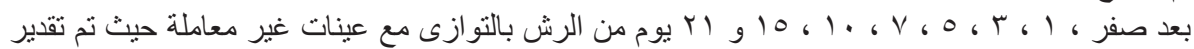

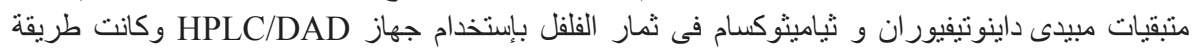

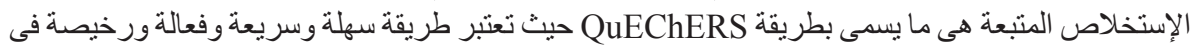

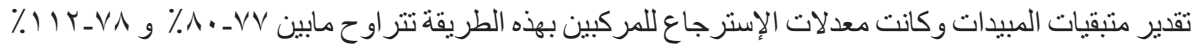

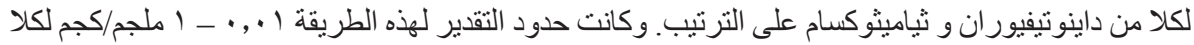

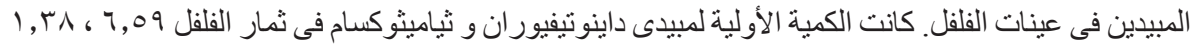

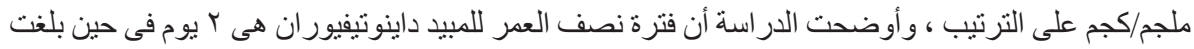

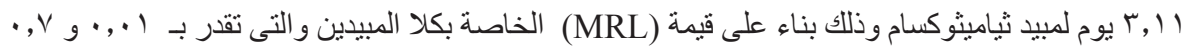

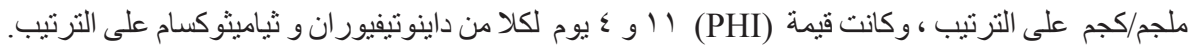

